American Journal of Pharmaceutical Education 2014; 78 (5) Article 101.

\title{
FACULTY DEVELOPMENT
}

\section{Engaging External Senior Faculty Members as Faculty Mentors}

\author{
Seena L. Haines, PharmD, ${ }^{a}$ and Nicholas G. Popovich, $\mathrm{PhD}^{\mathrm{b}}$ \\ ${ }^{a}$ Lloyd L. Gregory School of Pharmacy, Palm Beach Atlantic University, West Palm Beach, Florida \\ ${ }^{\mathrm{b}}$ College of Pharmacy, University of Illinois at Chicago, Chicago, Illinois
}

Submitted January 19, 2014; accepted April 14, 2014; published June 17, 2014.

\begin{abstract}
A small nonprofit private college with limited resources and a high proportion of junior faculty developed a nontraditional external faculty mentor program in the summer of 2011 in response to the American Association of Colleges of Pharmacy (AACP) faculty survey data regarding the professional development needs of pharmacy faculty members. Experienced faculty members with national reputations from other colleges and schools of pharmacy were hired as consultants to serve as mentors for assigned faculty members. Program goals were to provide directed, individual mentorship for pharmacy practice and basic science faculty members, expand peer review of faculty teaching prowess, and enhance monthly faculty development programming. The latter was based upon the specific needs assessment of the faculty. Program outcomes reported will include faculty satisfaction (AACP faculty survey data) changes over time, achievement of board certification for clinical faculty members and other credentialing, and other benchmarks, eg, publications, grant funding, service engagement (site development, professional organizations), after the implementation of the nontraditional faculty-mentoring program.
\end{abstract}

\section{INTRODUCTION}

The greatest good you can do for another is not just to share your riches but to reveal to him his own.

Benjamin Disraeli

Faculty development is fundamental to the success of colleges and schools of pharmacy as it can play a critical role in promoting academic excellence and innovation in a climate of decreased funding, fluctuations in student enrollment, and faculty mobility. ${ }^{1}$ Faculty development covers a broad range of activities designed to refresh or assist faculty members in their diverse roles, and is usually dependent upon faculty members' interests and expertise. Gruppen et al identified 3 driving forces of faculty development: public accountability, changing climate of health care delivery, and the need to sustain academic vitality. ${ }^{2}$

The need for faculty development programming is significant to support the complexity within academia and the demands from internal and external stakeholders, and to balance faculty members' responsibilities in teaching, scholarship, and service. ${ }^{3,4}$ Faculty mentor relationships as defined by Jacobi focus on 6 primary elements: achievement or acquisition of knowledge; emotional and psycho-

Corresponding Author: Seena L. Haines, PharmD, Professor of Pharmacy Practice and Associate Dean for Faculty Palm Beach Atlantic University, Gregory School of Pharmacy, PO Box 24708, West Palm Beach, FL 33416-4708. Tel: 561-8032713. Fax: 561-803-2703. E-mail: seena_haines@pba.edu logical support; career development and role modeling; reciprocal benefit between mentor and mentee; personal with direct interaction; and the mentor's experience, influence, and achievements. ${ }^{5}$

Formal faculty mentor programs have been associated with faculty job satisfaction and reduced turnover, enhanced productivity, and increased institutional commitment. Ideally, mentoring programs should be holistic in structure to meet developmental needs (ie, teaching, practice, research, service). It requires setting goals driven with clear expectations agreed upon in the mentoring relationship. Mentors should have adequate training and experience to meet the dynamic and evolving needs of the mentee., There are key factors that can support or impede professional development. The 4 domains involve people and interpersonal relationships, institutional structures, personal considerations and commitments, and intellectual and psychosocial characteristics. ${ }^{7,8}$

Mentors, mentees, and organizations benefit from mentoring relationships. Outcomes include increased productivity, organizational stability, socialization, communication, retention of employees, support of cultural diversity, and improved succession planning. Ideally, a mentoring program should link to other personal practices, eg, professional development training programs, performance appraisals, and systems of reward and recognition. Typically, faculty members with mentors feel more confident than their peers, and demonstrate enhanced teaching effectiveness, productive research, and career satisfaction. ${ }^{7,8}$ The 


\section{American Journal of Pharmaceutical Education 2014; 78 (5) Article 101.}

goal of the external mentor program was to develop an individual faculty member; strengthen teaching skills; motivate and inspire faculty members to plan, learn, collaborate and grow; guide faculty members towards personal goal setting; and increase faculty retention.

\section{PROGRAM DESIGN}

Founded in 2001, the Palm Beach Atlantic University Gregory School of Pharmacy (PBAGSP) is a small, private institution with 35 full and part-time faculty members, including the administration. Since early 2003, the school conceptualized and initiated a faculty enrichment and development program. Initial emphasis was placed on the development of an orientation checklist for new faculty hires and an informal, "buddy system" mentor program that paired junior faculty members with more experienced faculty mentors. The program provides the foundation for the success of the school's faculty members. The program is designed to foster the retention of diverse, highly qualified faculty members; to refine curriculum and teaching strategies; strengthen the research agenda; foster faculty citizenship internally and externally; and foster faculty collegiality as it relates to teaching, service, and scholarly works.

The faculty enrichment program consists of monthly sessions led by faculty volunteers and 2 annual summer retreats. Administrative oversight was originally provided by a faculty standing committee comprised of faculty members representing the diverse disciplines within the school, but was later transferred to the dean for faculty.
Based upon American Association of Colleges of Pharmacy (AACP) faculty survey data regarding the professional development needs of pharmacy faculty members, coupled with the high proportion of junior faculty members relative to the number of experienced faculty members in the school, a nontraditional external faculty mentor program (crossinstitutional) was initiated in 2011.

In 2010, scores were low on 5 of the AACP survey questions (Table 1) relative to national norms in the areas of teaching, service, and scholarship; career development; and acculturation into an academic setting. This was the impetuous that led to the establishment of a non-traditional faculty development approach.

Three experienced faculty members ( 2 of whom were the authors of this paper) with national reputations from other colleges and schools of pharmacy were hired as consultants to serve, along with 2 internal faculty members, as mentors for 13 faculty members. The 13 mentees were assistant professors with 5 years or less at the school, assistant or associate professors new to the school but with less than 5 years of expertise elsewhere on a nontenure track, or mid- or senior-level faculty members who desired to advance into an administrative role. Appendix 1 demonstrates the program's target, process, and key objectives. Program goals were to provide directed, individual mentorship for pharmacy practice and basic science faculty members, expand peer review of faculty teaching prowess, and enhance monthly faculty development programming. The latter was based upon the results of the annual faculty development needs assessment survey.

Table 1. AACP Faculty Survey Data on Faculty Development (2010-2013) for Palm Beach Atlantic University Gregory School of Pharmacy Versus National Norms

\begin{tabular}{|c|c|c|c|c|}
\hline \multirow[b]{2}{*}{ AACP Survey Question } & \multicolumn{4}{|c|}{ Strongly Agree/Agree, \% } \\
\hline & $2010, \mathrm{~N}=\mathbf{2 8}$ & $2011,{ }^{a} \mathrm{~N}=20$ & $2012, \mathrm{~N}=22$ & 2013, $N=20$ \\
\hline $\begin{array}{l}\text { The performance feedback I receive is } \\
\text { effective (Q. 18) }\end{array}$ & $64.3(70.6)^{b}$ & $52.6(74.1)^{b}$ & $90.9(74.2)^{b}$ & $85(74.2)^{b}$ \\
\hline $\begin{array}{l}\text { I receive adequate guidance on career } \\
\text { development (Q. 33) }\end{array}$ & $71.4(66.3)^{b}$ & $63.1(69.3)^{b}$ & $81.8(70.3)^{b}$ & $90(68.9)^{b}$ \\
\hline $\begin{array}{l}\text { Programs are available for non-practice } \\
\text { faculty to orient them to the } \\
\text { pharmacy profession and professional } \\
\text { education (Q. 35) }\end{array}$ & $53.5(38.7)^{b}$ & $42.1(40.5)^{b}$ & $86.4(42.4)^{b}$ & $95(42.4)^{b}$ \\
\hline $\begin{array}{l}\text { Programs are available to me to } \\
\text { improve my teaching and to } \\
\text { facilitate student learning (Q. 36) }\end{array}$ & $92.9(83.9)^{b}$ & $100(85.7)^{b}$ & $100(86.4)^{b}$ & $95(87.5)^{b}$ \\
\hline $\begin{array}{l}\text { Programs are available to me that help } \\
\text { me develop my competence in } \\
\text { research and or scholarship (Q. 37) }\end{array}$ & $57.1(64.2)^{b}$ & $36.9(67.5)^{b}$ & $72.7(71.1)^{b}$ & $80(70.3)^{b}$ \\
\hline
\end{tabular}




\section{American Journal of Pharmaceutical Education 2014; 78 (5) Article 101.}

This article describes an external mentor model designed to stimulate the growth and productivity of faculty members. Additionally, the justification for the initiative, design, implementation, and impact of this nontraditional faculty mentoring program is described, as well as the overall metrics from all mentees. Finally, descriptive outcomes of 1 external mentor are discussed. Limitations and lessons learned that might benefit other colleges and schools of pharmacy when developing a similar mentoring program are communicated.

Daloz described a mentor/protégé interaction model (protégé literally means grooming) that has been demonstrated to be effective at aiding adults through career transitions. He reported that effective mentor/protégé interactions balance 3 key elements: support, challenge, and a vision of the protégé. ${ }^{9}$ However, this model may present problems for underrepresented persons who because of their experiences, cultural perspectives, and values are not comfortable with the concept of grooming. An alternative is the network mentoring model. ${ }^{10,11}$ Its characteristics include, among others, that several individuals banning together to exchange psychosocial and vocational benefits guided by a skilled facilitator who is selected for the primary mentoring role. The facilitator, however, might not be able to answer all of the questions and/or address all of the specific needs of the mentee. Thus, the facilitator might secure or recommend others who can assist the mentee. With the networking model, there is an intentional avoidance of hierarchy and power within this relationship to develop a "win-win" scenario. ${ }^{12}$ In essence, the mentor and the mentee flourish.

\section{PROGRAM IMPLEMENTATION}

The faculty members were introduced to their mentor prior to the 2011-2012 academic year. Three external mentors were contracted to represent 3 primary disciplines: pharmacy practice, the social and administrative sciences, and the pharmaceutical sciences. External mentors were preferred over existing internal faculty members to help reduce the number of mentees assigned per mentor, and to provide the discipline-specific expertise lacking among existing faculty members, and because they had a proven track record of mentor achievements in teaching, scholarship, and service. Mentors were identified and invited by the dean for faculty and then matched with a faculty member based on discipline expertise, previous relationships in other academic training settings, study area consistent with the faculty mentee, and a demonstrated successful record of scholarship and funded research.

Each mentor met with the dean for faculty prior to beginning the program to discuss his/her roles and responsibilities, as well as periodically throughout the ac- ademic year as issues arose in process (eg, faculty follow up) or were identified at the midpoint and end-of-theyear documentation tracking. Key areas of focus for the external mentors and school faculty members included, among others, project management and goal setting, successful instructional strategies, grants and publications, civic engagement, precepting skills and clinical practice development, and work-life balance.

The external mentor program was equivalent to an internal mentor program in terms of requirements for the mentor and mentee. A faculty member had only 1 assigned mentor (internal or external). Each pair was expected to commit to regular meetings (virtual or face-to-face) and formulate agreed upon goals in different areas of importance for the faculty member. Although an overall structure was put in place, the program afforded the pairs flexibility on how to spend their time and energy to enhance the relationship and outcomes. A series of standardized mentee intake forms were completed and provided to all mentors to review in advance of the first brainstorming session for the academic year. A midpoint and summative annual review form was completed to provide accountability and reporting to administration on outcomes achieved and those in progress. At the end of each academic year, the mentor-mentee relationship was evaluated to determine whether the relationship should continue or an alternative pairing should be made. To date, only 1 mentor was replaced due to transitioning to parttime status at his home institution.

External mentors were expected to visit campus for face-to-face meetings with mentees once each semester. During that time, mentors provided a peer observation of teaching and shadowed practice faculty members at their clinical sites. Additionally, external mentors were scheduled to provide or participate in a development seminar or workshop, eg, examination writing, as part of monthly programming while visiting campus. Faculty mentors received an annual stipend as part of their contractual relationship with the school. An 11-item survey instrument based on programmatic goals and anticipated outcomes was created to evaluate faculty members' perceptions of the mentor program. The survey instrument was not content validated by an outside panel. The 4 mentees discussed in this study were told by their mentor that their responses would be confidential and that it was not necessary to answer every question unless they needed and/or felt compelled to do so. The mentees also were asked to describe their immediate and long-term needs from this relationship.

\section{PROGRAM OUTCOMES}

In terms of the overall impact of the external mentor program, changes in AACP faculty survey data (2010-2013) 


\section{American Journal of Pharmaceutical Education 2014; 78 (5) Article 101.}

for the school are shown in Table 1. The data validate improvements in meeting faculty needs related to professional development, individual feedback, career development, and creating programming to help individuals with faculty role development.

The school's pre- and post-implementation mentoring strategies for the 13 pharmacy practice (7), social administrative sciences (2), and pharmaceutical sciences faculty members (4) are presented in Table 2. Inclusion criteria for analysis were limited to only those mentees who were members of the school's faculty during the pre(2009-2010) and post-implementation period (2012-2013). Five faculty members were promoted during this timeframe. There were no significant differences among mentees' rank, board certification/certificate programs, or service. There was, however, a significant difference in number of peer-reviewed articles published $(\mathrm{p}, 0.002)$. The Wilcoxon signed rank test was used for nonparametric analysis because we could not assume a normal distribution.

Spontaneous feedback from mentees indicated a positive impact. Two of the 4 mentees reported that they were unable to contact their mentor as often as they should have. The mentees believed this was best explained by the adage "out of sight, out of mind," ie, because they did not encounter their mentor in the normal course of the day.

One mentee shared her inability to find time to contact her mentor when his assistance was needed. Part of this inability was the mentee's thinking her need was too small and she was therefore reluctant to ask. This mentee felt she did not use the mentor to the degree she should have. Another mentee shared that the frequency of conversations varied over time. The mentee indicated that the most beneficial contact was "one to one," rather than as a group with fellow mentees because more specific career questions could be asked and addressed. This mentee felt free to ask questions and thought the mentor's guidance was helpful and that he was "full of ideas." This mentee confided "as a junior faculty member it's not always easy to figure out what route to take, but the mentor has done a great job letting me know that I am on the right path to accomplish my goals." This mentee also indicated that the mentor relationship had helped her thought process regarding research hypothesis and scholarship and guided her toward opportunities appropriate for her career path. A third mentee shared that the mentor had been valuable in completing/helping her complete the "Teaching and Learning" certification process. Future goals for this faculty member were to discuss with her mentor career pathways, how to improve her classroom management skills, and how to connect with key pharmacy leaders to discuss research opportunities. The mentees indicated that completing assigned background readings prior to the mentor's on-campus visits enhanced group discussions and helped them to ask relevant questions.

\section{DISCUSSION}

Mentoring gained from outside of the Gregory School of Pharmacy benefited the school's faculty members. The reaction of the mentees to the networking mentoring model was positive. Each mentee needed individualized attention because specific needs were different from those of colleagues. Overall in the school, there was a distinct increase in the AACP faculty survey data since the mentoring plan was instituted. Correspondingly, there was an increase in mentees' belief that they were receiving guidance focused toward career development goals.

Table 2. Pre- and Post-Implementation of Mentoring Strategies $(n=13)$

\begin{tabular}{|c|c|c|c|c|}
\hline & 2009-2010 & $2011^{\mathrm{a}}$ & $2012-2013$ & $P$ \\
\hline \multicolumn{5}{|l|}{$\overline{\text { Faculty rank }^{\mathrm{b}}}$} \\
\hline Assistant & 8 & 7 & 4 & - \\
\hline Associate & 4 & 4 & 7 & - \\
\hline Professor & 1 & 2 & 2 & - \\
\hline $\begin{array}{l}\text { Board certification (\% faculty) } \\
\text { New board certification or practice credential }\end{array}$ & 23 & 28.5 & 21.3 & NS \\
\hline Scholarship (\% of faculty) & & & & $0.002^{\mathrm{c}}$ \\
\hline Authored peer-reviewed publications & 50 & 50 & 64.1 & \\
\hline Authored chapters/textbooks & 14.2 & 7.1 & 14.3 & \\
\hline Authored abstract/posters & 42.7 & 57.1 & 64.2 & \\
\hline Received internal/external grants & 7.1 & 14.2 & 21.4 & \\
\hline $\begin{array}{l}\text { Presentations ( } \% \text { of faculty) } \\
\text { Invited podium presentation } \\
\text { (local, state, national, or international) }\end{array}$ & 28.4 & 42.7 & 42.7 & NS \\
\hline
\end{tabular}




\section{American Journal of Pharmaceutical Education 2014; 78 (5) Article 101.}

Institution implementation of formal development sessions has helped non-practice/basic science faculty members orient themselves within the profession of pharmacy and within professional education. Along with these development sessions, the continued availability of programming to increase teaching to facilitate student learning has proven to be valuable from the faculty standpoint. This could be assessed further through a review of student-course and student-instructor evaluations in core curriculum course work. The implemented mentoring strategy has increased respondents' development of competence and behavioral changes in relation to their teaching, research/scholarship, and professional involvement beyond the walls of the school. For example, several faculty members have earned certifications, such as in pharmacotherapy and medication therapy management and as a certified diabetes educator. Also, there has been an increase in the number of abstracts submitted for national professional organization meetings and resultant poster sessions over the past 2 years. There remains a need, however, to translate these into manuscripts accepted for publication in similar fashion to Mundt. ${ }^{13}$

Mundt described a successful external mentor program as part of an institution-wide initiative to improve research productivity in a nursing program. The external mentor was invited by the faculty mentee to enter into a 1-year agreement, with meetings occurring at the mentor's home institution or at professional meetings that both attended. The dean of the school engaged qualified, interested mentors with the university's and school's strategic direction. Objective measures of success tracked were mentees' grant applications for extramural funding, manuscripts submitted, and invitations for development workshops.

The Mundt program created a positive environmental ethic of high achievement associated with external exposure to successful individuals. Similar to our experience at PBAGSP, faculty members saw the mentor relationship as a special opportunity and wanted to perform well in meeting agreed upon goals. The faculty felt supported and less vulnerable to internal competition and isolation. Further, these faculty felt the sincere interest of their mentor to see them flourish in their faculty role. Other similar subjective benefit included: improved focused faculty work patterns, faculty felt supported and less vulnerable to internal competition and isolation.

Using external mentors has advantages and disadvantages. Advantages include an individual who is outside of the current milieu of the mentee's institution and therefore not influenced by the institution's environment, leadership, or politics. In addition, information shared with the mentor is less likely to come back to "haunt" the mentee during promotion and tenure decisions.
Disadvantages of using external mentors include that the person is not as accessible as an in-house mentor would be, ie, the mentee cannot drop by the office to discuss an issue with the mentor. Nor can the mentor easily observe the faculty member in action to provide feedback on the mentee's teaching skills and strategies. Instead, these interactions must be planned for when the external mentor visits the mentee's campus. Face-to-face meetings are optimal to connect because nonverbal behaviors enrich these meetings. Scheduling meetings during the narrow windows of time the mentor is physically on campus can be difficult. The external mentor is challenged to be diligent and maintain contact with the mentee. Correspondingly, the mentee must be diligent to remain in contact with the mentor. Lastly, the external mentor might be unfamiliar with the institutional culture, dynamics, politics, etc. This may result in the mentor being unable to help mentees navigate specific institutional processes.

Our research involved a small number of faculty members at a private school of pharmacy. Thus, results might not be germane to a larger, private school of pharmacy nor at a land grant, research-intensive school of pharmacy. In addition, the number of faculty members mentored by the outside faculty member was small and all were in nontenure, clinical tracks. Further, the results span only the years since implementation of the outside mentor concept. Additionally, there was no control group of junior faculty members to rule out "confounding" factors within the school and/or university that might have helped the faculty members with needed mentoring.

During the mentor program implementation, faculty development programming was modified from a single distinctive topic per month model to a workshop-based model where 2-3 prominent themes were selected by the faculty member based on feedback from a survey. In addition, external mentors were scheduled to provide a workshop as part of their commitment. As such, a limitation may exist as to what extent this modified development approach influenced the improvements in the AACP faculty survey data. There was no opportunity to evaluate from a student perspective how the faculty development programs in teaching and instruction influenced student learning and skill development and whether a faculty member's teaching skills improved.

\section{SUMMARY}

This research demonstrated that engaging an outside mentor was successful at providing faculty development for junior/mid-career clinical faculty members. External mentors with no supervisory role encouraged faculty members to self-evaluate and reflect on their various faculty roles and responsibilities. Mentors provided faculty 


\section{American Journal of Pharmaceutical Education 2014; 78 (5) Article 101.}

members with freedom to discuss their assumptions about teaching, scholarship, and practice, and to examine disjunctions between them.

\section{ACKNOWLEDGEMENT}

Authors would like to acknowledge Dr. Jamie Fairclough for assisting with statistical analysis, and Drs. Stuart Haines and Scott Akers for assisting with implementation of the mentoring and faculty development program.

\section{REFERENCES}

1. Bergquist WH, Phillips SR. Components of an effective faculty development program. J High Educ. 1975;(46)2:177-211.

2. Gruppen LD, Simpson D, Searle NS, Robins L, Irby DM, Mullan PB. Educational fellowship programs: common themes and overarching issues. Acad Med. 2006;81(11):990-994.

3. Boyce EG, Burkiewicz JS, Haase MR, et al. Essential components of a faculty development program for pharmacy practice faculty. Pharmacotherapy. 2008;28(10):245e-268e.

4. Metzer AH, Hardy YM, Jarvis C, et al. essential elements for a pharmacy practice mentoring program. Am J Pharm Educ. 2013;77 (2):Article 23.
5. Berk RA, Berg J, Mortimer R, Walton-Moss B, Yeo TP. Measuring the effectiveness of faculty mentoring relationships. Acad Med. 2005;80(1):66-71.

6. Centra J.A. Types of faculty development programs. J High Educ. 1978;49:151-162.

7. Skeff KM, Stratos GA, Mygdal T, et al. Faculty development: a resource for clinical teachers. J Gen Intern Med. 1997;12(2):S56S63.

8. Zinn LF. (1997). Supports and barriers to teacher leadership: reports of teacher leaders. [Unpublished doctoral dissertation]. Greeley, CO: University of Northern Colorado.

9. Daloz L. Effective Teaching and Mentoring: Realizing the Transformational Power of Adult Learning Experience. San Francisco, CA: Jossey-Bass; 1996: 209-235.

10. Hubbard GT, Atkins SS. The professor as a person: the role of faculty well-being in faculty development. Innov High Educ. 1990; 20(2):117-128.

11. Mclean M, Cilliers F, Van Wyk JM. Faculty development: yesterday, today and tomorrow. Med Teach. 2008;30(6):555-584.

12. Haring MJ. Networking mentoring as a preferred model for guiding programs for underrepresented students. In: Frierson HT, ed. Diversity in Higher Education. Greenwich, CT: JAI; 1997:63-76.

13. Mundt MH. An external mentor program: stimulus for faculty research development. J Prof Nurs. 2001;17(1):40-45.

Appendix 1. Program Target, Process, and Key Objectives

I. Mentor Program Target Audience

1. Junior faculty (assistant professor with 5 years or less at PBA)

2. Assistant or associate professor new to PBA but less than 5 years' experience elsewhere on a non-tenure track

3. Mid or senior level faculty desiring to advance into administrative roles

II. Program Goals - The overall goal of the PBA-GSOP mentoring program is to support the members of our faculty by:

1. Developing the individual faculty member.

2. Strengthening teaching skills.

3. Motivating and inspiring faculty to plan, learn, collaborate and grow.

4. Guiding faculty towards personal goals.

5. Promoting faculty retention.

III. The mentoring program objectives are to:

1. Administer the program at the school level in concert with the University faculty development programming.

2. Structure the program in collaboration with the professional growth and development committee (PGD).

3. Provide the Mentor-Mentee Development Plan (MMDP) and other associated forms to develop mentor-mentee relationships and track outcomes.

4. Request voluntary participation by senior faculty and contract with external mentors for each representative discipline. a. Establish contract agreements with external mentors in the area of faculty discipline.

5. Provide all standardized forms and expectations to mentors and mentees.

6. Share outcomes with central administration. 